\title{
EXPLORANDO AS FORÇAS DA ESCRITA \\ NO ACONTECIMENTO LOUCURA
}

\author{
Regina Longaray Jaeger ${ }^{\star}$ Tania Galli Fonseca $\star \star$ \\ RESUMo
}

Neste estudo, apresentamos as análises dos encontros da pesquisadora com os escritos de uma mulher internada em um hospital psiquiátrico. Traçamos um recorte cartográfico do agenciamento loucura para perceber os corpos nos quais se expressa o acontecimento escrever. Entendemos que a escrita se encarna em certos fluxos que compõem seu corpo; é efeito dos encontros com os elementos do mundo, que constituem o agenciamento loucura/doença mental. Exploramos as forças que se operam nas palavras e os modos que a escritora minora a língua Em alguns escritos destacamos as três condições relativas à literatura menor e da variação da língua: coletiva, desterritorializada, política.

Palavras-chave: cartografia esquizoanalítica; literatura menor; loucura.

\section{EXPLORING THE FORCES OF WRITING IN MADNESS EVENT}

\begin{abstract}
This paper we present the analysis of the researcher's encounters with the writings of a woman hospitalized in the psychiatric hospital. We set a cut of the cartographic agencement madness to see the bodies that express the event writing. Writing, in the perspective of the multiplicity, expressed events, the remaining states of things that constitute the body of the writer. We understand that writing is incarnated in some streams that make up your body, is the effect of encounters with the elements of the world, which constitute the agencement where madness / mental illness. We explore the forces that operate in the words, and the ways that the writer minor language, dodging the ruling stated. In some writings highlight the three conditions for the minor literature and language change: collective, deterritorialized, politics.

Keywords: schizoanalytic cartograph; minor literature; madness.

\footnotetext{
^ Psicóloga. Doutoranda do Programa de Pós-graduação em Psicologia Social e Institucional da Universidade Federal do Rio Grande do Sul, Pesquisadora e colaboradora de grupo de pesquisa "Corpo, Arte e Clínica".

E-mail: reginaja@portoweb.com.br Universidade Federal do Rio Grande do Sul. Endereço: Universidade Federal do Rio Grande do Sul. Instituto de Psicologia, Programa de Pós-Graduação em Psicologia Social e Institucional. Ramiro Barcelos, 2600 - Sala 300j. Santana - Porto Alegre, RS - Brasil. CEP: 90035-003.

E-mail: tfonseca@via-rs.net
}

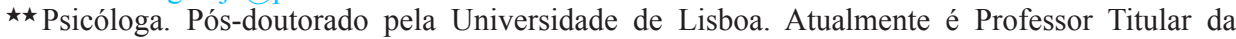


Apresentamos as análises dos encontros da pesquisadora com os escritos de uma mulher, Claudina Pereira, que esteve internada na área asilar de um hospital psiquiátrico durante quase três décadas. Encontros que foram sendo traçados e resultaram em dissertação de mestrado defendida junto ao Programa de Pós-Graduação em Psicologia Social e Institucional do Instituto de Psicologia da Universidade Federal do Rio Grande do Sul.

O Hospital Psiquiátrico São Pedro foi fundado em 1884 e, ainda hoje, opera três ações: acolhimento asilar de moradores destituídos de qualquer vínculo fora do Hospital, internação para usuários portadores de transtornos mentais agudos e serviços ambulatoriais. Trata-se de território extremamente demarcado por concepções de doença, de tratamento corretivo, reabilitador e subjetivação tutelada.

A "Mulher dos papéis" (codinome escolhido pela escritora) apaixonou-se pelas letras quando as conheceu no Ginásio: "Amava os verbos desde criança. Verbos indicam ação". Sob a forma de avisos, anotações, interrogações, escritos musicais, expressa os acontecimentos da vida pessoal, institucional e familiar. Recolhe fragmentos daquilo que passa, do que ouve, do que a afeta: escritos de memorandos, vozes hospitalares, músicas do rádio, programas de TV. Fragmentos de sons, visões- expressões que subsistem nas matérias vivas ou não, que a compõem - precisam ser anotados e repassados para cadernos, agendas antigas, papéis de rascunhos. Fluxos de palavras que emergem na conjugação de diferentes agenciamentos que compuseram sua existência no Hospital São Pedro.

Foi realizado um recorte cartográfico do agenciamento loucura para perceber os corpos onde se expressa o acontecimento "escrever". Escrever, tomando as referências da cartografia, não tem outra função senão "ser um fluxo que se conjuga com outros fluxos - todos os devires - minoritários do mundo" (DELEUZE; PARNET, 1998, p. 63). Implica seguir os rizomas, conjugar os fluxos desterritorializados. Fluxos desterritorializados de políticas públicas, de discursos terapêuticos, de reformas, de regimes de distribuição de medicação entre outros tantos. Escrever, portanto, é fazer aparecer corpos e acontecimentos. Exploramos as forças que se operam nas palavras, fazendo a língua sair fora de seus enunciados dominantes, fora de um sujeito e fora das organizações dualistas psicologizantes. Trata-se de um processo que imprime à palavra um devir-minoritário, exprime transformações dos corpos em devires que vão muito além do codificado, do admitido, do previsto.

O mundo composto de matérias em devir, de partículas virtuais que se atualizam, corpos que se modificam instantaneamente, imediatamente a cada novo encontro, a cada acontecimento, constitui-se uma multiplicidade. Em outras palavras, "uma multiplicidade não tem sujeito nem objeto, mas só determinações, grandezas, dimensões, que não podem crescer sem que ela mude de natureza" (DELEUZE; GUATTARI, 1989, p. 14-15). O acontecimento escrever, nessa multiplicidade, exprime um conjunto de transformações produzidas nos corpos. A cada encontro, matérias entram em devir, em transformação instantânea e expressiva. Matérias virtuais se atualizam e se modificam imediatamente a cada acontecimento. 
Num agenciamento não há sujeitos, mas estados maquínicos expressivos em devir, que se compõem de corpos e de acontecimentos. Em revezamento, reenviam-se uns aos outros. Formam âmbitos complementares, mas não correspondentes (DELEUZE; PARNET, 1998, p. 86). O âmbito conteúdo é formado pelos corpos, os estados de coisas. O âmbito expressão é o que "diz" o estado de coisas (DELEUZE, 2005, p. 57).

A palavra escrita pela "Mulher dos papéis" escapa de um código de enunciados dominantes, extravasa um determinado estado de coisas instituído, esquiva significações constantes e vazias já conhecidas. Desloca-se para constituir-se diferentemente. Em nosso entendimento, a partir das contribuições de Gilles Deleuze, Michel Foucault e Félix Guattari, as palavras desta mulher expressam acontecimentos, nos encontros dela com os elementos do mundo, especialmente, os elementos que constituem os agenciamentos, que encarnam o acontecimento loucura/doença mental, no qual ela está inserida. Escrever, portanto, é um destes acontecimentos que se encarnam em certos fluxos que fazem o corpo daquela mulher, marcado de história, que a faz sentir e falar. Há embate de forças de que a fazem dizer, interrogar, para rasgar a história, encontrar saídas, fazendo expressar pela palavra, pequenas rupturas que a afetam, desterritorializando de seus contornos de doente mental nos quais ficou encerrada. Pelo uso de determinadas expressões, ela faz emergir certa potência disruptiva da palavra, enclausurada pelos movimentos estabilizadores e representativos que surgem a partir do século XVIII, no saber-poder psiquiátrico e psicológico (FOUCAULT, 1997). Logo, quando falo a palavra "loucura", emprego-a em um sentido em que subsistem corpos denominados loucos. Mas de onde vem esta palavra? "Enlouquecer" é um conceito datado. Emerge em uma determinada configuração de forças. Subsiste em corpos diferentes, singulares, cujas marcas são consideradas erros.

A pesquisa realizada buscou trazer a emergência da expressão da vida plural que nos desamarra e transforma, onde é possível inventar.

Diante destas considerações nos questionamos: o que essas palavras contemporâneas da "Mulher dos papéis" têm ainda a dizer após mais de 200 anos de silenciamento institucional, construído através de pesadas dicotomias e clausuras do pensamento?

Parte da engrenagem do agenciamento hospital psiquiátrico, o fluxo desejante desta escrita, que se materializa através dos códigos linguísticos da língua portuguesa, expõe, de um lado, o que há de mais tradicional nas relações entre os saberes médicos e os doentes mentais, corroborando e aliando-se a eles, e, de outro lado, abre brechas nas formalizações destes saberes, mostrando as engrenagens mais íntimas do hospital e provocando as relações de forças em que está inserida, intensificando-as.

A "Mulher dos papéis" seleciona, recolhe palavras que encarnam as forças da vida que encontra no maquinismo hospitalar, faz proliferar forças que nos desacomodam e nos fazem deslocar nossos saberes tradicionais. 
O Hospício

é um

Despotismo?

Reformas:

Antes, De-

pois.

Reforma ou

Construção de prédios?

Outros mais?

Outros mais?

(Claudina Pereira, Cadernos de anotações).

Quais forças do contemporâneo constituem a "palavra louca"? E como estão em jogo no acontecimento loucura? Fazer falar o louco, para quê?

\author{
Já desenvol- \\ vi milhões \\ de Questio- \\ nários. \\ Que são Bar- \\ reiras Intrans- \\ poníveis? \\ Amo o Silêncio \\ Profundo \\ e muito difi- \\ cilmente o con- \\ sigo ter.
}

No mundo em que

vivemos: vivemos testan-

do o Sempre!

(Claudina Pereira, Cadernos de anotações).

Congelados pelas representações dicotomizantes que buscam fazer corresponder o que vemos e falamos e do "já vi isto", facilmente recaímos em sobrecodificações e institucionalizações. Enrijecidos, tornamo-nos incapazes de nos afetar pelas forças que operam microdeslocamentos, defasagens que os encontros na vida nos possibilitam. 
Não se trata de resgatar a linguagem da loucura/doença mental, rejeitada durante séculos. Propomo-nos a transgredir o logos da razão, desfazer divisões, rachar as palavras de modo a exprimir o jogo de forças em que estão implicadas. Muito além do patológico, a experiência da loucura pode, pela linguagem, exprimir um pensamento que se esboça. Expressão que desorganiza formas, interrogações que rompem correspondências evidentes e lógicas, expondo os agenciamentos de forças intensivas e do mundo hospitalar/asilar.

O que hoje somos capazes de ver, sentir e dizer da loucura? O interesse por autores como Foucault, Deleuze e Guattari decorre de pensar uma realidade viva, em permanente transformação, desmanchando as dicotomias para mostrar aquilo que se sente, se percebe e se diz. Há apenas facetas, recortes, clarões sob certos jogos de forças históricas (DELEUZE, 2005, p. 62).

O acontecimento "loucura" é encarnado pela conexão, disjunção e conjugação de diferentes corpos, diferentes fluxos-cortes. O uso de ferramentas tecnológicas, medicação, eletrochoques, terapias menos invasivas, admitidos por forças sociais históricas presentes do século XX, alterou forma e substancia, tanto do conteúdo quanto da expressão.

\author{
Onde São Precisos \\ Dar Provas de \\ Sensatez até o \\ Fim for me. \\ Onde os Padres e \\ Freiras Baixam. \\ Perto de mim, Limpar \\ o que já está limpo, \\ Sabem o que é Isso? \\ O Lugar de Loucos é \\ no Hospício.
}

(Claudina Pereira, Cadernos de anotações).

Esta "Mulher dos papéis" expõe com clareza: se lugar de loucos é no hospício, por que então precisar dar provas de sensatez? Limpar o que já está limpo? "Dar provas de sensatez" constitui-se um acontecimento, efetuado pelo estado de coisas-agenciamento hospitalar- institucionalizante de quem sabe quem é o louco e que sabe da necessidade e da impossibilidade de dar provas de sensatez, nesta realidade criada, "neste lugar de loucos". Sabe que "no lugar de loucos" - forma de conteúdo - já está comprovada a "loucura"- -substância de expressão e qualquer questionamento faz prova confirmatória. Instigada pela "condição de loucura" em que vive é substância de conteúdo. Agenciamento hospitalar asilar é lugar de limpeza, de anulamento das cabeças vazias e desmemoriadas. Expressa um funcionamento, um regime de intervenção, que se diz terapêutico e simultaneamente fabrica a loucura isolamento com que trabalha: administração do tempo, 
obrigações, convencimento. E este regime precisa ser afirmado constantemente. A loucura, para ser eliminada, curada, precisa ser confirmada em sua realidade específica (FOUCAULT, 2003, p. 172). E isto ela questiona: "para que dar provas de sensatez quando tudo já está determinado, quando o lugar de loucos é no hospício?" O que constitui o conteúdo, a matéria do asilo, exprime a razão do asilamento, do louco, do desmemoriado, do crônico. Interrogatórios encarnam esta busca de lucidez inatingível.

Mas como surgiriam o novo e as transformações do estado de coisas?

Entre o visível e o enunciável, existem apenas relações divergentes, em constante atualização. Dentro de diagramas que se sucedem, relações de força encadeam descontinuidades. Diagrama aqui entendido enquanto conjunto de determinadas relações de forças, puras matérias e puras funções, que subsistem em determinada formação histórica (DELEUZE, 2005, p. 81). Escrever é um modo de expressar esta luta, ajudando a cartografar a mesma. Misturas de relações de forças, relativamente plurais, pontos de criação relativamente livres, sem começo e nem fim. Escrever se articula ao ato de pensar a própria experiência. A "Mulher dos papéis" fala em nome próprio, porque o nome próprio opera uma individuação, um certo estado de corpos, potências impessoais e físicas. Assim, "menos você será uma pessoa ou um sujeito, mais você será um 'coletivo' que encontra outros coletivos, que se conjugam e se cruzam com outros, reativando, inventado, predizendo, operando individuações não pessoais" (DELEUZE; PARNET, 1998 p. 138). E assim, a mulher dos papéis expressa o agenciamento hospitalar.

\section{Por uMa Língua MenOR}

Para Deleuze e Guattari (2005), os enunciados linguísticos, como palavras de ordem, não se ocupam com informar, mas exprimir agenciamentos dentro dos quais se produzem (DELEUZE; GUATTARI, 2005, p. 12). Por constantes linguísticas, Deleuze entende tomar certas variáveis de uma língua como modelo organizador e político. Uma língua estabelece um padrão sintático dominante, pois "é um marcador de poder antes de ser um marcador sintático". A gramaticalidade é condição prévia de submissão às leis sociais, aos regimes de verdade, às relações de forças. Os saberes científicos são uma manifestação desta luta de forças. "A unidade de uma língua é, antes de tudo, política" (DELEUZE; GUATTARI, 2005, p. 46).

Mas a tomada de poder por uma língua não faz da sua existência uma língua maior, nos advertem estes autores. Não há, pois, dois tipos de língua, mas dois tratamentos dados a uma língua: ora extrair das variáveis, constantes, ora extrair das variáveis, novas variáveis (DELEUZE; GUATTARI, 2005, p. 49). Não há como separar menor e maior enquanto duas línguas, mas como dois tratamentos, dois usos ou funções dentro de uma mesma língua.

Tomamos de Deleuze e Guattari (1977) o conceito de literatura menor, retirado das análises realizadas na obra de Kafka,escritor judeu tcheco que escreveu em alemão oficial, próprio à cultura e ao comércio europeu do início do 
século, que luta para se homogeneizar e dominar. Kafka opera uma língua desterritorializada da língua de uma minoria alemã opressiva, estendendo-a em variações contínuas. Sobrecarregou as variáveis da língua para fazê-la vibrar como "testemunha da presença não-localizada de um discurso indireto no interior de qualquer enunciado.” (DELEUZE; GUATTARI, 2005, p. 50). Uma língua menor é a potência de subversão dentro de uma língua maior. "O que uma minoria faz em uma língua maior” (DELEUZE; GUATTARI, 2005, p. 47).

Pudemos apreender na escrita da "Mulher dos papéis" os três modos de expressão minoritária, de trabalho de variação da língua dentro da língua maior, fazendo aparecer os confrontos de línguas dentro de uma mesma língua, destacados por Deleuze e Guattari (1977).

Em primeiro lugar, quanto ao grau de desterritorialização de uma língua, a "Mulher dos papéis" faz aparecer variações linguísticas no monólogo tradicional sobre a loucura em alguns de seus escritos.

A canção, quem manda na

minha vida sou Eu"(Bis)

Do verbo convencer.

Na Faculdade de Psiquia-

tria: Só pra ver o que está

Acontecendo.

Na Faculdade de Psicologia

Só Dignas-

Logo: Quando não estamos

na Psiquiatria, estamos na

Psicologia.

(Claudina Pereira, Cadernos de anotações).

Assim, potencializa efeitos de modificação, intensificando o uso menor da língua, proliferando efeitos cambiantes. Potencializa as palavras misturando sonoridades. Utiliza o verbo no infinitivo, puros acontecimentos impessoais, explorando as misturas dos corpos e os efeitos destas misturas. O que liga este conceito à escrita de "Mulher dos papéis" é a sua capacidade de criação de uma língua dentro da língua portuguesa dominante. Jeito singular de expressar, recria uma língua diferente dentro da língua portuguesa usada nos discursos do saber/ poder psiquiátrico/psicológico.

A segunda, é que o uso da língua menor é um ato político. Escrever é brandir instrumento político. A marca da literatura menor é mostrar o que é imperceptível. O tratamento menor da língua recusa constantes, onde uma outra história se agita, se ramifica, estabelece elos, modifica agenciamentos. 
E a terceira característica é de que, na literatura menor, "tudo adquire um valor coletivo" (DELEUZE; GUATTARI 1977, p. 27). Não há enunciação individualizada. O que se escreve expressa agenciamentos coletivos de enunciação. Uma obra menor não fala por si, mas mostra o agenciamento que o escritor faz falar. Diferente de um porta-voz que representa e que fala por si e por um conjunto de pessoas, o escritor mostra o agenciamento minoritário que o compõe. A presença viva não localizada das minorias força a desterritorialização do próprio agenciamento majoritário. Potencial de criação e variação que recusa as constantes linguísticas.

Que é ficar
neutra
numa situa-
ção?
Que é Indi-
ferença e
Desprezo?
--
Que é cola-
borar e Par-
ticipar?
Que é sus-
pender?
Quando
por tempo
Indeterm-
inado?

(Claudina Pereira, Cadernos de anotações).

Mas “A linguagem não é a vida, ela dá ordens à vida; [...] Em toda palavra de ordem, mesmo de um pai a seu filho, há uma pequena sentença de morte - um Veredicto, dizia Kafka" (DELEUZE; GUATTARI, 2005, p. 13). E uma palavra de ordem exerce apenas uma função coextensiva à linguagem. A linguagem é sempre de um dito reportado a outro. Não consiste na comunicação de uma experiência, mas na transmissão do que o ouviu. A linguagem expressa o discurso indireto do agenciamento. "Existem muitas paixões em uma paixão, e todos os tipos de voz em uma voz, todo um rumor, glossolalia: isso porque todo o discurso é indireto" (DELEUZE; GUATTARI, 2005, p. 13). O ponto de partida da linguagem é "um ouvi dizer", é sempre de um dito a outro dito, de modo que é sempre transmissão funcionando como palavra de ordem (DELEUZE; GUATTARI, 2005, p. 13). Produzir uma língua menor é mostrar devires não conservadores. 
Onde e que Eu saiba só

existem pra morada, as

Paredes e o teto da Secre-

taria do Meio Ambiente.

Todos só pensam em

colecionarem carros, jóias

e Apartamentos, não é?

(Claudina Pereira, Cadernos de anotações).

Não vivemos, amamos, estudamos, falamos apenas segundo um modo padrão; produzimos cotidianamente pequenos deslocamentos, pondo-os em variação, muitas vezes imperceptíveis. Eclode em cada um, polifonias de vozes, efeito de discurso indireto com os quais nos afetamos e produzimos expressões singulares. Por vezes, nos tornando estrangeiros dentro de nossa própria língua. Cada um de nós pode fazer falar uma língua menor, singular e coletiva, como o tratamento minoritário da língua maior, modelar. É esta estranha novidade expressiva que consideramos nos escritos da "Mulher dos papéis".

Quando

Tenho certeza

Absoluta

Que quer dizer cer-

teza abso-

luta?

(Claudina Pereira, Cadernos de anotações).

Devemos, então, distinguir o maior - que supõe um sistema dominante e constante - e a minoria, que "é o devir de todo o mundo, seu devir potencial por desviar do modelo". Devir é diferença de diferença, fuga, desterritorialização (DELEUZE; PARNET, 1998, p. 13). Assim, a palavra do louco pode tornar-se minoritária dentro do discurso da saúde, que é expressão do domínio de uma maioria. Para isto, é preciso que ela produza a disrupção, o desmonte do agenciamento, a avaria. A palavra do louco, se é um subsistema ajustado de um sistema maior, dominante, é absorvida e torna-se funcional ao discurso hegemônico.

Consideramos menores três modos de expressão que conseguimos apreender na escrita em questão.

Escrita telegráfica: os indícios de desterritorialização estão num novo modo de escrever, denso, econômico, curto. Notas rememorativas, rápidas, bilhetes que são feitos para não esquecer. Escrever para não esquecer é o que sustenta sua escrita. "Pequenos anúncios" indefinidos, nomes próprios que não são das pessoas, mas de um agenciamento coletivo (DELEUZE; PARNET, 1998, p. 85). Intercessores que imprimem a velocidade aos estados de 
coisas. Esta "Mulher" faz rachaduras com suas notas, abre uma guerra fazendo aparecer uma disputa ainda inconclusa, uma luta entre saberes. Luta presente desde a entrada da psicologia no HPSP.

Será, será

A psiquia-

Tria sempre

Foi maior que

A Psicologia?

(Claudina Pereira, Cadernos de anotações).

Verbos no infinitivo: Ênfase no acontecimento. Utiliza o verbo no infinitivo sem sujeito gramatical, expressando o puro acontecimento, linhas de devir que cortam diferentes corpos, matérias sonoras, apropriações dos ditos ouvidos no hospital, família, instituição hospitalar, doença mental.

Proibir-se?

Assumir-se?

Que é isso?

Isso, existe?

Comigo: Os evitados-os que

Passaram a ser evitados

Ignorados -Todos.

Expurgar,

Excluir,

Que é colaborar

E participar?

Que é suspender?

(Claudina Pereira, Cadernos de anotações).

Escritas sob formas de perguntas: Podemos constatar duas formas de interrogação. Primeiro destacamos aquelas que se apropriam do procedimento de anamnese, desterritorializando o método de trabalho terapêutico e reterritorializando-o em perguntas. Mas nada que evidencie uma minoração da língua. Aqui, evidencia-se uma imitação.

Rouba o procedimento do interrogatório para potencializar suas próprias perguntas para com isto ganhar mundos. Mas também sabe a armadilha criada, pois também precisou aliar-se aos procedimentos institucionais, sabe que são os mesmos que cronificam e criam a realidade do louco desmemoriado. Aprendeu a lição. Sabe que é louca, se apropriou e aprendeu a jogar com as forças das palavras legitimadas. Desconfiada, permanece afirmando sua luta agonística: 
"agora até moças de 20 anos me dão remédio". Expressão de uma luta permanente, de forças desiguais, cuja matéria se expressa em alguns escritos menores, forças rumorosas de um corpo em devir.

O outro modo de perguntar, denominamos de "falsas perguntas". Constituem-se de modos de fazer afirmações disruptivas nas perguntas. Acentuando afirmações através de interrogações, intensifica a provocação do estado de coisas, faz aparecer uma genealogia do hospital. Apropria-se do procedimento institucional mas desterritorializa-o através da afirmação de luta entre os movimentos, as lutas, disputas entre forças mais ou menos conservadoras. E nesta luta, desvela o codinome dos loucos, dos ignorados. A cada pergunta, uma palavra de ordem que aponta devires, atos, ações em movimento:

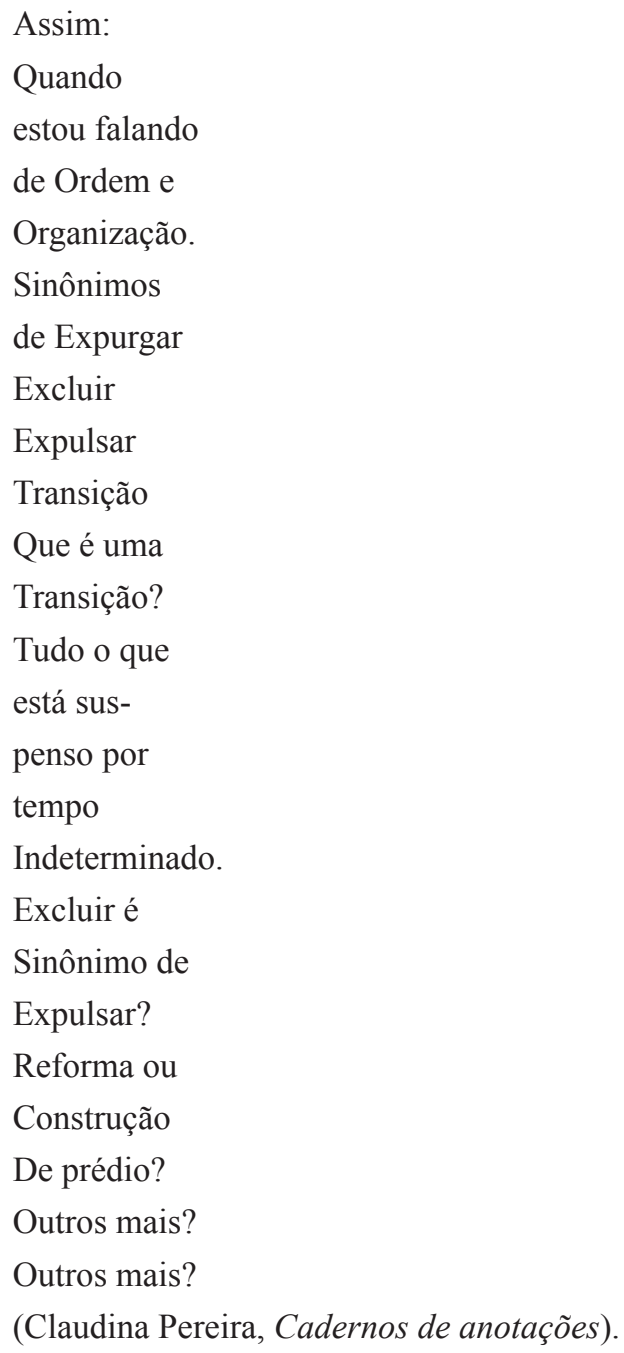


Interrogações-afirmativas que forçam o estranhamento dessa "Mulher" diante de determinada organização do mundo, fazendo quebras, abrindo brechas, deixando escapar minorias que povoam o agenciamento, lutas, agonismos nas inúmeras reformas, codinomes dos loucos. Apesar da aquisição de um nome, terão a cidadania plena ignorada. Ocupa-se da língua portuguesa, faz sinais que abrem fluxos de guerra pela palavra, nesta realidade que é ensinada a ela e aos técnicos. Burla a medicação, interroga o funcionamento do estado de coisa do hospital psiquiátrico:

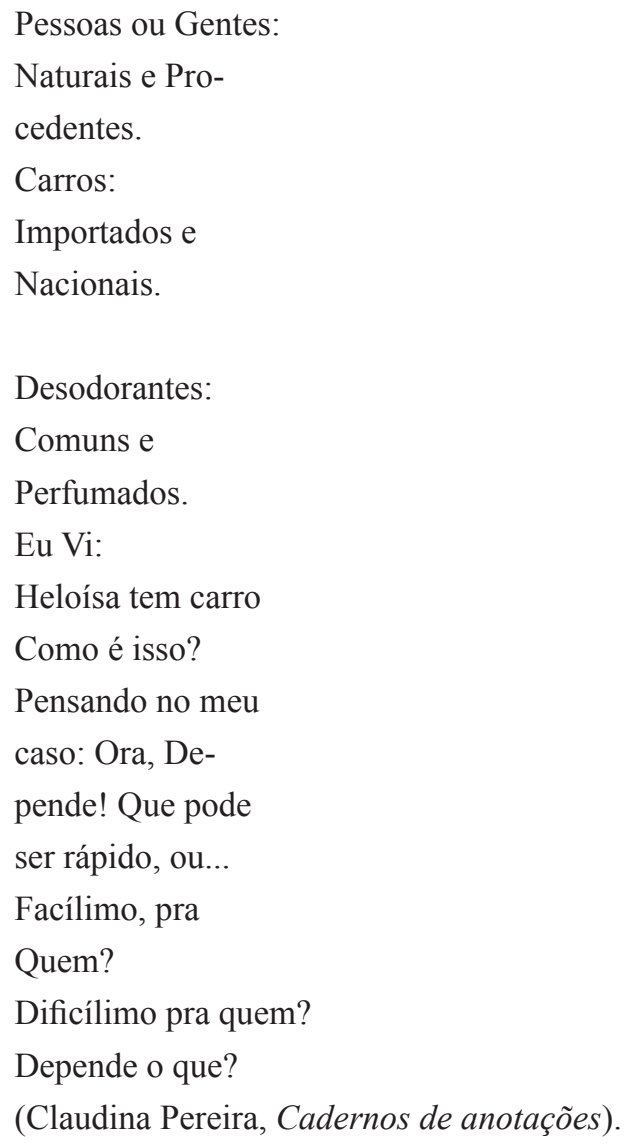

Verbo no infinitivo, telegráfico e interrogativo-afirmativo. Três modos de sobrecarregar a palavra, alcançar o máximo de potência da vida e rachar o estado de coisas do acontecimento loucura. Faz aparecer uma genealogia, a luta entre os ignorados, dos sem posses, dos sem família, dos sem mediação do Estado, dos expostos às forças da vida, do desconto, da inferioridade, da mais-valia institucional. Jogo eminentemente político de forças entre saberes. A "Mulher dos papéis" sabe que é uma peça deste jogo entre a afirmação da vida e a contenção. 
Denominados "ignorados", muitos usuários não tinham sequer nome e qualquer existência jurídica ainda nos primeiros anos deste século, condição que levou a assistência jurídica do hospital a uma busca desta identidade. Embora seja um avanço no que se refere ao tratamento e respeito ao doente asilar, a "Mulher dos papéis" sabe desta impossibilidade dos ignorados deixarem de ser evitados. Funcionamento que irrompe pela escrita. Faz mostrar que mesmo com o direito soberano de ter um nome, não significa concessão de reciprocidade entre indivíduos livres e iguais, que são direitos garantidos pelo Estado. Expressa a comunidade minoritária dos confinados, ignorados, erradicados da vida e da interrogação-afirmativa que diz da impossibilidade de retorno ao cotidiano comum.

Constituída por 30 anos, através do saber institucional, como então enfrentar "lá fora"? Não precisa mais "dar provas de sensatez", pois "já sabe, já aprendeu a lição". E depois disto, ter de enfrentar a exclusão/inclusão num mundo que não teve lugar para ela. Excluir, expulsar. Fabricar-se em pleno estado de miserabilidade. Há um acontecimento-loucura que ultrapassa os muros do hospital. A "Mulher dos papéis" faz pequenas rachaduras com palavras que dizem dos ignorados. Como sair para "fora" se a realidade destas vidas inexiste fora da palavra de ordem do ato presumido terapêutico? Sabe que as demarcações e os códigos territoriais são extremamente duros e têm várias faces.

Que é Acesso?

Que é Excluir?

Que é Excluir?

Logo: Só dou Aces-

so a gentes

Polidas!

Excluir: quando

sim, quando não.

Bis- Novamente:

Excluir, quando

Sim, quando Não!

Acesso: quando

$\underline{\text { Sim, quando Não! }}$

Materiais de Trabalho

o que todos sempre

me Passaram. 
O que tenho em mãos

Apenas uma chave

de armário.

(Claudina Pereira, Cadernos de anotações).

Hoje, no hospital, aos usuários-moradores que lá permaneceram, restou pouca coisa. Enquanto funcionava o poder psiquiátrico asilar tradicional, a " $\mathrm{Mu}$ lher dos papéis" resistia a esta hegemonia hospitalar escrevendo, interrogando incessantemente. Enfraquecidos os fluxos do asilamento por outras forças mais "limpas", é preciso constituir outra face de doente mental. Institucionalizada, caiu na armadilha. Despossuída das vassalidades e recompensas, desanima, sem deixar os registros deste estado de coisas, "preferindo o teto e as paredes".

Do verbo: per-

seguir.

Estou sem Prédio

e estou morando

em Prédio do Go-

verno. Perseguida por Lou-

cos! Stress! Vim pa-

rar no Hospício.

Não vou a Fes-

tas e a Passeios.

Prefiro, o teto e

as paredes.

Minha vida é

sem paradeiros

dados a persegui-

ção de Loucos

vivo sempre em

stress!

(Claudina Pereira, Cadernos de anotações).

Sabe que não há lugar para os crônicos e para os loucos desvalidos. "Estou sempre pensando em fugir, mas fugir para onde? Existe a Porto Alegre sadia e Porto Alegre dos loucos".

Ela conhece as divisões e saber/poder, que cria a realidade da loucura. Como enfrentar tais forças, como desmanchar este agenciamento? Ao poder de escrever e não ser beneficiada, responde com seu poder de não escrever e nem receber mais vassalidades, presentes, antigas agendas. Mas continua expressando mesmo sem escrever mais. Qual autonomia pode se constituir numa instituição de confinamento? 
O rearranjo dos fluxos na troca de unidade hospitalar ocasiona um estancamento no fluxo da escrita. Não crê no poder de mudar seu modo de vida pela escrita, mesmo que fosse através de uma contaminação do poder psiquiátrico. Agora, escreve para não se tornar uma desmemoriada. "Pode ocorrer de se perder tudo de novo". Perder o quê? Seus pertences guardados, papéis escritos, que estavam nos armários que foram escancarados quando foi fechada a unidade Bleuler em que estava. Perderam a memória dela, contida nos escritos dela. Memória espoliada e dissipada. De peça operativa, doente mental, torna-se peça operativa indigente no agenciamento asilar. Ao escrever sabe que muitos lucram, inclusive a instituição, os residentes, a academia. Menos ela.

Esta mulher expõe o embate das forças dos movimentos mais inovadores e conservadores, expressando as próprias fragilidades destes movimentos dentro de uma máquina abstrata, loucura que continua confinando moralmente, dividindo o mundo em dicotomias, selecionando experiências, e anexando-as a saberes legitimados. Sabe que, apesar da entrada de novas forças inovadoras na disputa dos saberes da loucura/doença mental permanecemos ainda bastante ensurdecidos ao que foi silenciado, ao que foi ignorado.

\section{Nota}

${ }^{1}$ Os espaços entre as frases e a ortografia dos escritos seguem a forma original dos textos da escritora Claudina Pereira arquivados no Acervo da Oficina de Criatividade do Hospital Psiquiátrico São Pedro.

\section{REFERÊNCIAS}

DELEUZE, G. Foucault. São Paulo: Brasiliense, 2005.

DELEUZE, G.; GUATTARI, F. Mille plateau: capitalisme et schizophrénie. Paris: Minuit, 1989.

DELEUZE, G.; GUATTARI, F. Kafka: por uma literatura menor. Rio de Janeiro: Imago, 1977.

DELEUZE, G.; GUATTARI, F. Mil Platôs: capitalismo e esquizofrenia. São Paulo: Editora 34, 2005. v. 2.

DELEUZE, G.; PARNET, C. Diálogos. São Paulo: Escuta, 1998.

FOUCAUlT, M. A História da Loucura na Idade Clássica. São Paulo: Perspectiva, 1997.

FOUCAULT, M. Le pouvoir psychiatrique. Cours au Collège de France (19731974). Paris: Gallimard/Seuil, 2003.

Recebido em: 17 de janeiro de 2011

Aceito em: 13 de agosto de 2012 
